\title{
Preparation of Biodegradable and Low-Cost Lignin-Based PVOH Carbon Fibers Prepared by Electrospinning
}

\author{
Amir Hamzah Siregar ${ }^{1,2}$, Aditia Warman ${ }^{3}$, Mahyuni Harahap ${ }^{1,4}$, Grace Nainggolan ${ }^{1,2}$, \\ Dellyansyah Dellyansyah ${ }^{1,2}$, and Saharman Gea ${ }^{1,2^{*}}$ \\ ${ }^{1}$ Cellulosic and Functional Materials Research Centre, Universitas Sumatera Utara, \\ Jl. Bioteknologi No. 1, Medan 20155, Indonesia
}

${ }^{2}$ Department of Chemistry, Faculty of Mathematics and Natural Sciences, Universitas Sumatera Utara, Jl. Bioteknologi No. 1, Medan 20155, Indonesia

${ }^{3}$ Department of Physics, Faculty of Mathematics and Natural Sciences, Universitas Sumatera Utara, Jl. Bioteknologi No. 1, Medan 20155, Indonesia

${ }^{4}$ Department of Chemistry, Universitas Sari Mutiara Indonesia, Jl. Kapten Muslim, Medan 20124, Indonesia

\author{
*Corresponding author: \\ email: s.gea@usu.ac.id \\ Received: June 14, 2021 \\ Accepted: September 2, 2021
}

DOI: $10.22146 /$ ijc. 66606

\begin{abstract}
A polyvinyl alcohol (PVOH)/lignin nanofiber was prepared by the electrospinning method as a precursor for biodegradable and low-cost carbon fibers. $\mathrm{PVOH} 15 \%$ was dissolved in water, and various concentration of lignin $(5,10,15,20$, and 25\%) was added. The presence of lignin in PVOH solution increased the viscosity and conductivity. From SEM analysis, $P V O H$ solution produced smooth fiber, whereas the addition of lignin produced fibers in bead forms. The presence of lignin above $20 \%$ in $P V O H$ did not produce spun-fiber. FTIR analysis confirmed that lignin was able to form hydrogen bonds with $P V O H$. TGA analysis showed that PVOH/lignin nanofibers had the highest residual mass, i.e., $40 \%$ at $600{ }^{\circ} \mathrm{C}$. The morphology of the carbon fibers showed flake forms with many pores and had $58.07 \%$ carbon content.
\end{abstract}

Keywords: lignin; carbon fiber; electrospinning; polyvinyl alcohol

\section{- INTRODUCTION}

In the last few years, the demand for carbon fibers (CF), such as vapor grown carbon nanofibers (VGCNF), multi-walled carbon nanotube (MWCNT), and singlewalled carbon nanotube (SWCNT) [1-2], has increased significantly in various industrial applications. CF has superior properties compared to other carbonaceous materials, which are high mechanical properties and strength-to-weight ratio, fatigue resistance, and low cost [3]. The demand for CF was reported to have globally increased almost twice every year [4]. However, the growth rate of the CF industry has not been able to supply to the fast-growing demand, especially due to the main precursor for $\mathrm{CF}$, i.e., polyacrylonitrile (PAN) is expensive and petroleum-based [5]. Hence, the search for inexpensive CF alternatives based on biobased resources, biodegradable, and low-cost precursors is the main topic of current investigation to cope with large-scale manufacturing constraints caused by PAN. These polymers, as biobased, biodegradable, and low-cost, include lignin [6], cellulose [7], and biomass resins [8].

Lignin, the most abundant non-cellulosic polymer on earth, is complex aromatic (phenolic) macromolecules present in the cell wall of plants. It comprises three main phenylpropanoid monomers or precursors: coniferyl, sinapyl, and p-coumaryl alcohol [9]. Lignin has been studied for its various applications, such as in the production of biomass from crude bio-oil as energy generation [10], composite carbon nanofibers [11], compatibilizer [12], and carbon fibers [13]. The carbon content and chemical structures of lignin showed potential for carbonized material production, especially carbonized lignin fibers [14]. Lignin was isolated from either 
hardwood or softwood, whose chemical structures differed. It was also found as the major by-product in paper industries.

Lignin could be extracted by several methods, such as lignosulfonates, alkali lignin, kraft lignin, and organosolv lignin. Each method produced a different lignin character with different purity and lignin fraction sizes. These properties influenced the fiber spinning formation and the quality of CF products [3]. It was estimated that the cost of lignin precursor was lower than the PAN precursor. However, the manufacturing process of lignin-based CF could be more expensive than PAN's, as the currently preferred method was melt-spinning. The process involved complex and accurate control of the lignin, spinning conditions, and treatment temperature. Lignin required critical controlling at the melt-spinning step because it naturally oxidized partially [5].

Electrospinning is a fiber spinning technology to produce fibers from micro to nano-sized diameters. Fibers are produced as nonwoven fiber mats, or they can be in the shape of aligned fiber strings. In the electrospinning process, an electrical field is injected into the polymer solution. The solution jet is stretched and elongated by electrical forces, while the viscoelastic forces prevent it from breaking. Then, the thin solution jet dries before reaching the ground surface, where fibers are collected [15]. Pure lignin solution usually does not have enough viscoelasticity for spinning. Therefore, it is blended with another polymer known as binder solution, such as electrospun poly (ethylene oxide) (PEO), polyacrylonitrile (PAN), and poly (vinyl alcohol) $(\mathrm{PVOH})$ [14]. $\mathrm{PVOH}$ is a semicrystalline polymer with high carbon amount (54.5\%) and hydroxyl groups, making it easy to use as a precursor to producing carbon materials [16]. In this work, we presented a simple and straightforward experimental method to get carbon nanofibers precursor by the electrospinning of lignin solutions at room temperature with the addition of polymer in a single step and carbonization to produce carbon nanofibers.

\section{- EXPERIMENTAL SECTION}

\section{Materials}

Lignin alkali, partially soluble 13.4 wt.\% loss on heating
$316{ }^{\circ} \mathrm{C}, \mathrm{pH}: 6.5\left(25{ }^{\circ} \mathrm{C}, 5 \%\right.$ aqueous solution, d: $1.3 \mathrm{~g} / \mathrm{mL}$ ) was purchased from Sigma Aldrich, USA. $\mathrm{PVOH}$, fully hydrolyzed (Mw approx. 60,000) with viscosity $20^{\circ} \mathrm{C}$ ( $4 \%$; water), degree of hydrolysis $\geq 98.0 \%$, was purchased from the same supplier. No further purification was carried out to lignin and $\mathrm{PVOH}$ used for the aqueous solution for electrospinning.

\section{Procedure}

\section{Polymer solution preparation}

Preliminary experiment, $\mathrm{PVOH} 10 \%(\mathrm{w} / \mathrm{v})$ was prepared by dissolving $10 \mathrm{~g}$ of $\mathrm{PVOH}$ in $100 \mathrm{~mL}$ distilled water for $4 \mathrm{~h}$ in aquatic reflux. This concentration was used to prepare lignin/PVOH blend solution throughout the experiment. PVOH powder was gradually added and constantly stirred during the dissolving stage to avoid agglomeration of particles at $110^{\circ} \mathrm{C}$ and $600 \mathrm{rpm}$ for $6 \mathrm{~h}$ to dissolve the polymer completely. This process resulted in a colorless and viscous $\mathrm{PVOH}$ solution. After that, lignin was added to $\mathrm{PVOH}$ solution with different concentration ratios PVOH to lignin of (10:0); (10:5); (10:15); (10:20); and (10:25) v/w\% by using an ultrasonic for $6 \mathrm{~h}$. The electrospun polymer solutions were characterized for the conductivity and viscosity.

\section{Electrospinning process}

The fresh polymer solution was directly electrospun by horizontal electrospinning (basic series electrospinning unit Brand NLI, Nanolab Instruments Sdn Bhd, Malaysia) at room temperature with the following conditions: (i) a voltage of $15 \mathrm{kV}$; (ii) feed rate of $0.1 \mathrm{~mL} / \mathrm{h}$; (iii) needle tip-to-collector distance of $15 \mathrm{~cm}$; (iv) disposable 18-G syringe; and (v) speed of collector $300 \mathrm{rpm}$. The collector was coated with aluminum foil sheets to attach the fibers. Next, the electrospun mat was dried at room temperature and stored for further characterization.

\section{Carbonization process}

$\mathrm{PVOH} /$ lignin nanofiber was carbonized in a furnace under a nitrogen atmosphere. Pre-carbonization was carried out from 25 to $100^{\circ} \mathrm{C}$ with a heating rate of $5{ }^{\circ} \mathrm{C} / \mathrm{min}$. At $100^{\circ} \mathrm{C}$, the process was isothermally held for $30 \mathrm{~min}$. The second step was carried out at a temperature between 100 and $200{ }^{\circ} \mathrm{C}$ and a heating rate 
of $5{ }^{\circ} \mathrm{C} / \mathrm{min}$, then isothermally held for $30 \mathrm{~min}$. Next, the carbonization process was continued from 200 to $600{ }^{\circ} \mathrm{C}$ with a heating rate of $5{ }^{\circ} \mathrm{C} / \mathrm{min}$ and held isothermally for $1 \mathrm{~h}$. The morphology of carbon fiber was investigated by using SEM.

\section{Characterization}

Conductivity and viscosity. The conductivity and viscosity of the electrospun polymer solution were examined prior to the electrospinning process. A $10 \%$ PVOH was added to several different concentrations of lignin $(0,5,10,15$, and $20 \%)$. The electrical conductivity was examined by using Multiparameter Bench Meter Mi 180, Milwaukee, by immersing the probe into the solution without having bubbles trapped inside the sleeves. The conductivity value was displayed on the primary LCD. Meanwhile, the viscosity was determined by using HAAKE Viscotester 550. The homogenized sample solution was put into the viscometer tank at room temperature in the Kohlrausch flask below the viscometer. Both conductivity and viscosity tests were repeated three times.

Scanning electron microscopy analysis. The surface morphology of samples was observed using scanning electron microscopy (SEM) Hitachi TM3030 (JEOL, Ltd., Tokyo, Japan) with accelerating voltage EHT of $20.00 \mathrm{kV}$, probe $=101 \mathrm{~Pa}$, and signal A = SE1. Samples were placed on an adhesive-backed carbon tape and secured to the specimen. After that, they were sputter-coated with a thin layer of gold alloy (SC 500 Emscope) to reduce charging during analysis.

Thermogravimetric analysis. The mass-loss characteristics of the materials used in this project were characterized by using a thermogravimetric analyzer (model TASC 414/4 NETZSCH). The specimen was heated from 25 to $900{ }^{\circ} \mathrm{C}$ with a heating rate of $10^{\circ} \mathrm{C} / \mathrm{min}$ under an argon atmosphere.

Differential scanning calorimetry analysis. The thermal properties of the samples were studied by using differential scanning calorimetry (DSC) X-DSC7000 (Hitachi medical system, Tokyo, Japan) in a range temperature between 30 and $250^{\circ} \mathrm{C}$ with a heating rate of $10^{\circ} \mathrm{C} / \mathrm{min}$.

\section{- RESULTS AND DISCUSSION}

\section{Morphological Characterization of Electrospun PVOH/Lignin Nanofiber}

The images from SEM for $\mathrm{PVOH}$ and $\mathrm{PVOH} /$ lignin electrospun nanofibers are shown in Fig. 1. Whereas the conductivity and viscosity are presented in Fig. 2. Lignin/PVOH-based fiber mats were produced by electrospinning technique, with the compositions of lignin corresponding to $\mathrm{PVOH}$ varied from $0,5,10,15$, 20, and 25\%. As shown in Fig. 1(a), PVA solution at 10\% concentration produced smooth, bead-free fibers with a diameter of $124.8 \mathrm{~nm}$. However, the addition of lignin $\mathrm{PVOH}$ solution produced fibers in bead forms. This might be due to the increase in viscosity of polymer solution with the presence of lignin. The viscosity was $4.4 \mathrm{Nm} / \mathrm{s}^{2}$ for PVOH $10 \%$, and $7.8,9.4,10.5,17.4$, and $23.6 \mathrm{Nm} / \mathrm{s}^{2}$ for $\mathrm{PVOH} /$ lignin solution ratio of $100: 5$, 100:10, 100:15, 100:20, and 100:25, respectively. The increase in the concentration of polymer solution has been reported to cause larger friction of fluid and hinder
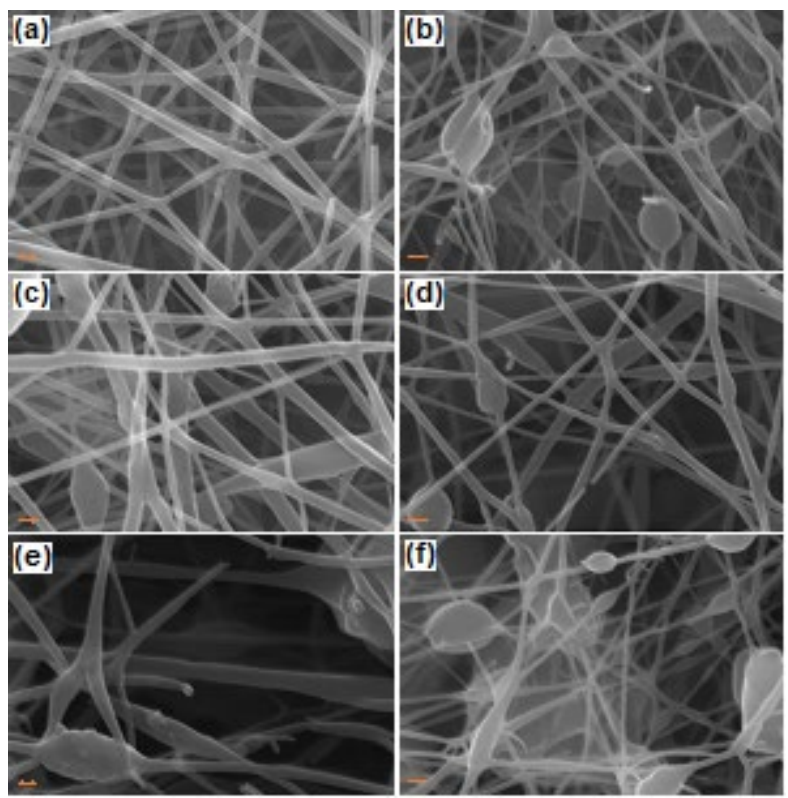

Fig 1. SEM images of electrospun $\mathrm{PVOH} /$ lignin nanofiber at different lignin concentrations: (a) $0 \%$; (b) $5 \%$; (c) $10 \%$; (d) $15 \%$; (e) $20 \%$; and (f) $25 \%$ lignin, with magnification of $3000 \times$. Scale bar $=200 \mathrm{~nm}$ 
electrostatic forces in attracting droplets to Taylor cone and polymer jets [17].

Moreover, SEM images (Fig. 1) revealed that the average diameters of spun-fibers decreased with the increase in the concentration of the lignin, such as from $63.38 \mathrm{~nm}$ at $5 \mathrm{wt} . \%$ lignin to $55.83,52.90,48.38$, and $42.43 \mathrm{~nm}$ at $10 \mathrm{wt} . \%, 15 \mathrm{wt} . \%, 20 \mathrm{wt} . \%$, and $25 \mathrm{wt} . \%$ lignin, respectively. This happened as salts in lignin increased the conductivity, as shown in Fig. 2. High conductivity increases the electrostatic charge density of polymer solution to produce thicker fiber. The same result was reported by another author who reported that $\mathrm{PVOH}$ solution could be readily electrospun, while bead-fibers were created with the addition of lignin [18]. More fibers with ribbon-shaped morphology were produced by increasing the amount of lignin in spin dope. Spin dope with high lignin amount had the tendency to form thin and tube-like jet/filament during electrospinning, which could further collapse with the rapid vaporization of solvent [19]. In this study, the presence of lignin onto PVOH with the concentration of $20 \%$ and $25 \%$ could not undergo electrospinning because of the cohesiveness of the solution. The viscosity of the polymer solution at these concentrations limits the followability of the polymer solution.

\section{FTIR Analysis}

The FTIR spectra for PVOH, commercial lignin, $\mathrm{PVOH}$ nanofiber, and $\mathrm{PVOH} /$ lignin nanofiber are shown

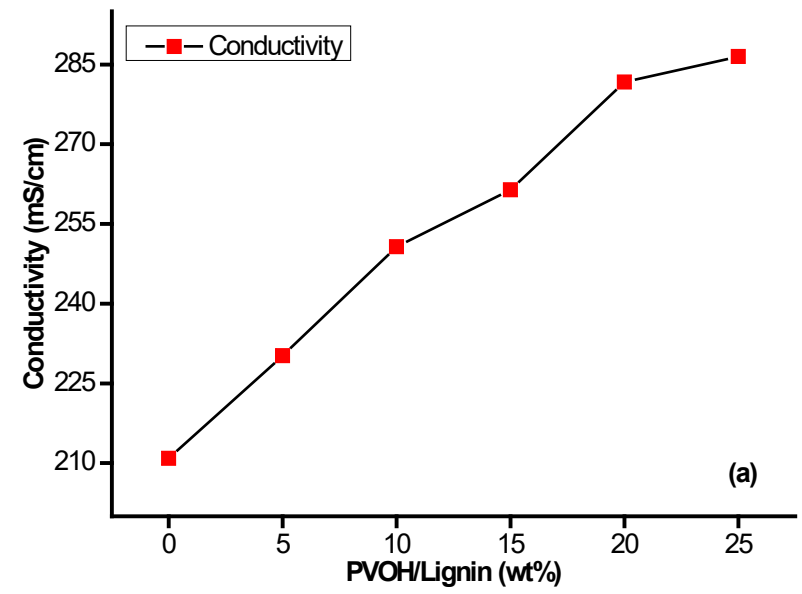

in Fig. 3. Regarding Fig. 3, several wavenumbers were selected to identify the lignin. Firstly, absorption bands between $3600 \mathrm{~cm}^{-1}$ and $3000 \mathrm{~cm}^{-1}$ attributed to hydroxyl groups in aromatic and aliphatic structures. $\mathrm{C}-\mathrm{H}$ stretching of the aliphatic and aromatic structure was observed at $2480 \mathrm{~cm}^{-1}$. C=O stretching of carboxyl groups was identified at $1705 \mathrm{~cm}^{-1}$. The peaks at 1600 and $1611 \mathrm{~cm}^{-1}$ attributed to the $\mathrm{C}-\mathrm{C}$ stretching of the aromatic skeleton and the vibrations of the aromatic rings. Vibrations of $\mathrm{C}-\mathrm{H}$ bonds in aromatic rings and $\mathrm{C}-\mathrm{O}(\mathrm{H})+\mathrm{C}-\mathrm{O}(\mathrm{Ar})$ stretching appeared at $1328 \mathrm{~cm}^{-1}$. The vibrations of $\mathrm{C}-\mathrm{H}$ bonds in aromatic rings were observed at $834 \mathrm{~cm}^{-1}$. These absorption bands were also

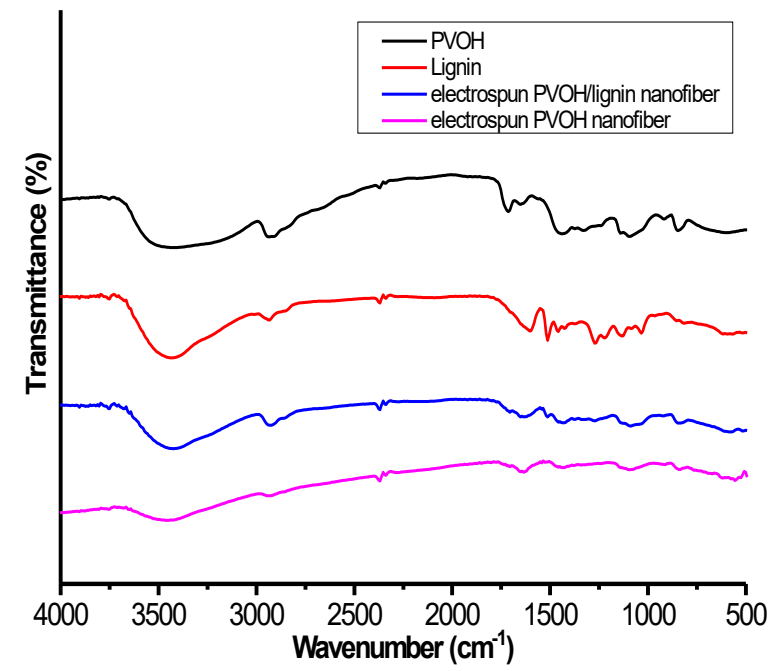

Fig 3. FTIR spectra of PVOH, lignin, $\mathrm{PVOH}$ nanofiber, and PVOH/lignin nanofiber

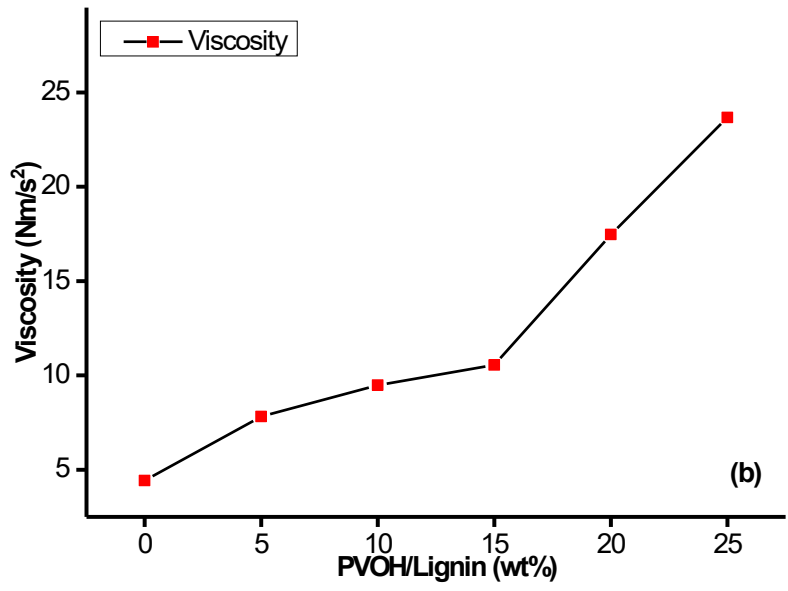

Fig 2. (a) The conductivity and (b) the viscosity of $10 \mathrm{wt} . \% \mathrm{PVOH}$ solution in distilled water at different lignin concentrations $0 \%, 5 \%, 10 \%, 15 \%, 20 \%$ and $25 \%$ 
reported by other authors [4]. FTIR also confirmed the chemical structures of $\mathrm{PVOH}$ nanofiber, showing dominant absorption peaks at 3650, 2941, 1733, 1428, 1090 , and $844 \mathrm{~cm}^{-1}$, which attributed to $\mathrm{OH}, \mathrm{CH}_{2}, \mathrm{C}=\mathrm{O}$, $\mathrm{CH}-\mathrm{C}-\mathrm{H}, \mathrm{C}-\mathrm{O}$, and $\mathrm{C}-\mathrm{C}$, respectively. The acetate group in the PVOH was represented in the $1959 \mathrm{~cm}^{-1}$ band [15].

Meanwhile, FTIR spectroscopy was used to investigate the blending of $\mathrm{PVOH}$ and lignin. In the hydroxyl-stretching region $\left(3000-3700 \mathrm{~cm}^{-1}\right)$, the $\mathrm{OH}$ in the PVOH was at $3650 \mathrm{~cm}^{-1}$. This band shifted to lower wavenumber $\left(3323 \mathrm{~cm}^{-1}\right)$ after the blending with lignin $(\mathrm{OH})$ due to a new hydroxyl bond formed during the blending process, either within the $\mathrm{PVOH}$ or between lignin and PVOH. FTIR analysis confirmed that lignin was able to form hydrogen bonds with $\mathrm{PVOH}$. The blending of $\mathrm{PVOH} /$ lignin film had formed a strong hydrogen bond between the hydroxyl groups in $\mathrm{PVOH}$ and lignin [20]. The interaction confirmed the excellent mechanical strength of the nanofiber precursor [21].

\section{Thermal Properties of Electrospun PVOH/Lignin Nanofiber}

The thermal properties of lignin, $\mathrm{PVOH}, \mathrm{PVOH}$ nanofiber, and $\mathrm{PVOH} /$ lignin nanofiber were studied using TGA and DSC analysis with a heating rate of $10{ }^{\circ} \mathrm{C} / \mathrm{min}$ under an argon gas atmosphere. Fig. 4 depicts TGA traces for pristine lignin, $\mathrm{PVOH}, \mathrm{PVOH}$ nanofiber, and $\mathrm{PVOH} /$ lignin nanofiber. All TGA traces showed three distinct regions. The first step was the elimination of water and moisture from the samples. The second was to remove some organic volatiles, and the last was to form amorphous or semicrystalline carbon [22].

The TGA curve of lignin showed dehydration from room temperature to $100{ }^{\circ} \mathrm{C}$. At this stage, there was $3 \%$ weight loss. Second, the thermal degradation of lignin between 225 and $350^{\circ} \mathrm{C}$. Last, lignin with a residual mass of approximately $35 \%$ at $600{ }^{\circ} \mathrm{C}$ provides lignin as a good carbon fiber precursor.

The TGA traces for $\mathrm{PVOH}$ nanofiber and $\mathrm{PVOH} /$ lignin nanofiber had the first weight loss observed from room temperature to $100{ }^{\circ} \mathrm{C}$. There was $5-10 \mathrm{wt} . \%$ weight loss at this temperature. The same result was observed in PVOH. Then, second weight loss occurred at

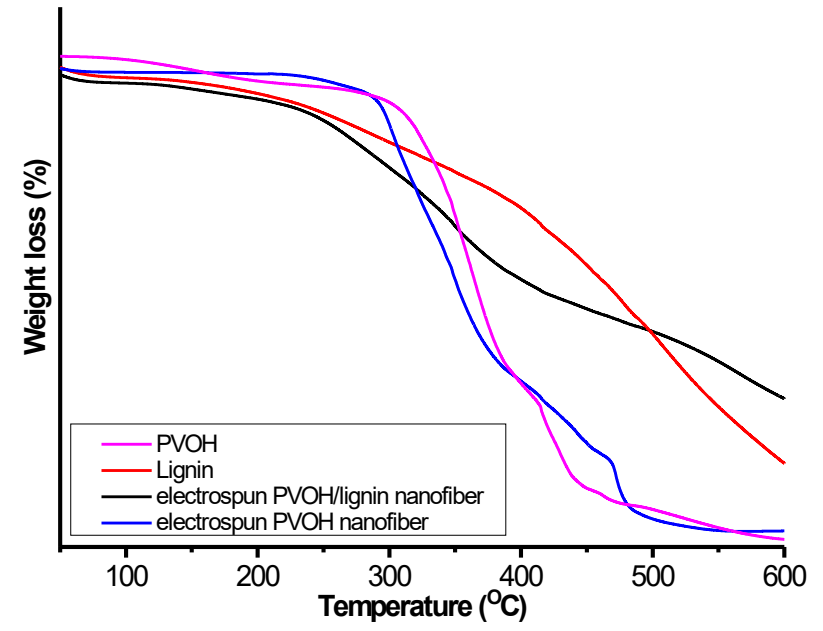

Fig 4. TGA curve of lignin, $\mathrm{PVOH}, \mathrm{PVOH}$ nanofiber, and $\mathrm{PVOH} /$ lignin nanofiber with a heating rate of $10^{\circ} \mathrm{C} / \mathrm{min}$

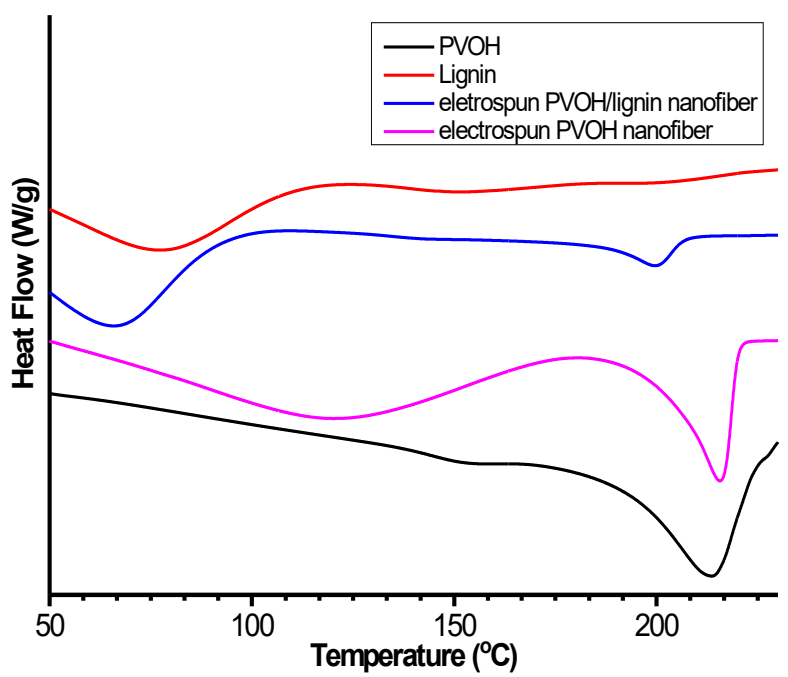

Fig 5. DSC thermogram for lignin, $\mathrm{PVOH}, \mathrm{PVOH}$ nanofiber, and $\mathrm{PVOH} /$ lignin nanofiber with a heating rate of $10{ }^{\circ} \mathrm{C} / \mathrm{min}$

$300{ }^{\circ} \mathrm{C}$ to $450{ }^{\circ} \mathrm{C}$ for $\mathrm{PVOH}$ and $\mathrm{PVOH}$ nanofiber. This region shifted to a lower temperature between 250 and $400{ }^{\circ} \mathrm{C}$ for $\mathrm{PVOH} /$ lignin nanofiber. At this stage, $\mathrm{PVOH}$ and $\mathrm{PVOH}$ nanofiber had lost more than $50 \%$ of their mass, while PVOH/lignin nanofiber lost only $30 \%$ of its weight. This was mainly associated with the decomposition of $\mathrm{OH}$ and acetate groups in $\mathrm{PVOH}$ and lignin [23]. Lastly, the decomposition of PVOH backbone structure for $\mathrm{PVOH}$ and $\mathrm{PVOH}$ nanofiber was observed at below $450{ }^{\circ} \mathrm{C}$, while it has a percent residue of $3 \%$. 


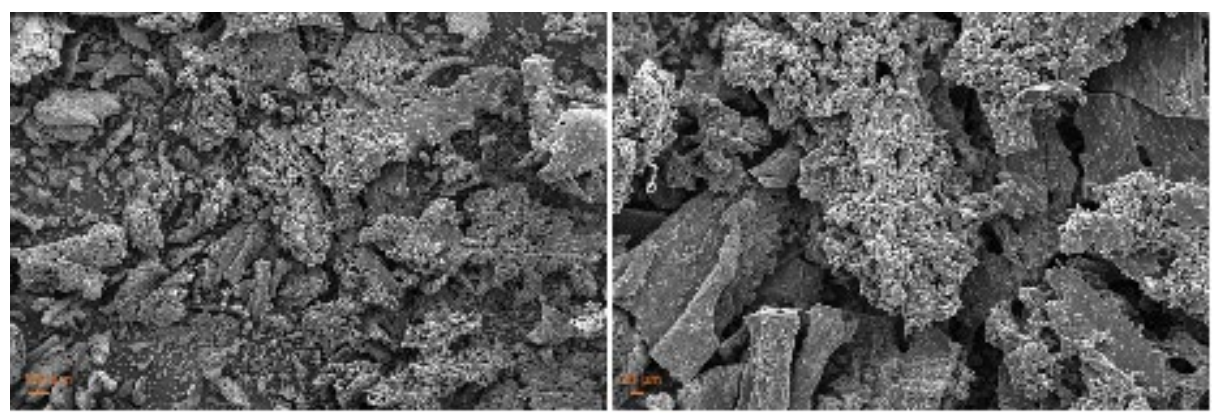

Fig 6. SEM-EDS analysis of lignin/PVOH based nanofiber with a magnification of $100 \times$ (left) and $300 \times$ (right)

However, PVOH/lignin nanofiber had the highest residual mass $\left(40 \%\right.$ at $\left.600{ }^{\circ} \mathrm{C}\right)$.

Fig. 5 shows DSC curves of lignin, $\mathrm{PVOH}, \mathrm{PVOH}$ nanofiber, and $\mathrm{PVOH} /$ lignin nanofiber. $\mathrm{PVOH} /$ lignin nanofiber had a peak at $70{ }^{\circ} \mathrm{C}$, which was associated with the dehydration of the sample. The melting temperature $\left(\mathrm{T}_{\mathrm{m}}\right)$ of $\mathrm{PVOH}$ and $\mathrm{PVOH}$ nanofiber was the same at $225^{\circ} \mathrm{C}$. In comparison, $\mathrm{PVOH} /$ lignin nanofiber has a $\mathrm{T}_{\mathrm{m}}$ of $200{ }^{\circ} \mathrm{C}$. This is due to a new hydroxyl bond being formed during the blending process, either within the PVOH or between lignin and PVOH, as shown in FTIR spectra.

\section{The Morphology of PVOH/Lignin Carbon Fiber}

The morphology of the as-spun fiber after carbonization is shown in Fig. 6. The sample was carbonized at $600{ }^{\circ} \mathrm{C}$ with a heating rate of $5{ }^{\circ} \mathrm{C} / \mathrm{min}$. The morphology of the carbon fiber was flake with many pores. In addition, SEM-EDS analysis showed that the carbon fiber had $58.07 \%$ carbon content, which was still low compared to commercial carbon fibers. In addition, fiber forms could not be observed after the pyrolysis, possibly due to the low compatibility between lignin and $\mathrm{PVOH}$. Other authors reported that $\mathrm{PVOH}$ melted during the isothermal treatment $\left(250{ }^{\circ} \mathrm{C}\right)$, producing higher curvature and fusing into the network structure [24]. This study concluded that PVOH/lignin could be an excellent precursor for carbon fibers. Another study reported that the carbonized lignin had mesopores and an amorphous graphitic structure [25].

\section{- CONCLUSION}

In this paper, electrospun PVOH/lignin nanofibers as carbon fiber precursors have been successfully prepared.
The spun fibers show smooth and good morphology, but it produces bead-fibers after the addition of lignin to $\mathrm{PVOH}$ due to low compatibility with PVOH. Meanwhile, lignin improves the viscosity and conductivity of the polymer solution. The presence of lignin at up to $20 \%$ in $\mathrm{PVOH}$ cannot produce spun-fiber. FTIR analysis confirms that lignin is able to form hydrogen bonds with $\mathrm{PVOH}$. TGA analysis shows that PVOH/lignin nanofibers have the highest residual mass, i.e., $40 \%$ at $600^{\circ} \mathrm{C}$. The morphology of the carbon fibers is flake with many pores, and the carbon content is $58.07 \%$.

\section{- ACKNOWLEDGMENTS}

This research was funded by the TALENTA USU with contract number 4167/UN5.1.R/PPM/2019.

\section{- REFERENCES}

[1] Zhang, J., Chevali, V.S., Wang, H., and Wang, C.H., 2020, Current status of carbon fibre and carbon fibre composites recycling, Composites, Part B, 193, 108053.

[2] Al-Saleh, M.H., and Sundararaj, U., 2009, A review of vapor grown carbon nanofiber/polymer conductive composites, Carbon, 47 (1), 2-22.

[3] Ding, R., Wu, H., Thunga, M., Bowler, N., and Kessler, M.R., 2016, Processing and characterization of low-cost electrospun carbon fibers from organosolv lignin/polyacrylonitrile blends, Carbon, 100, 126-136.

[4] Gea, S., Siregar, A.H., Zaidar, E., Harahap, M., Indrawan, D.P., and Perangin-Angin, Y.A., 2020, Isolation and characterisation of cellulose nanofibre and lignin from oil palm empty fruit bunches, Materials, 13 (10), 2290. 
[5] Baker, D.A., and Rials, T.G., 2013, Recent advances in low-cost carbon fiber manufacture from lignin, $J$. Appl. Polym. Sci., 130 (2), 713-728.

[6] Chio, C., Sain, M., and Qin, W., 2019, Lignin utilization: A review of lignin depolymerization from various aspects, Renewable Sustainable Energy Rev., 107, 232-249.

[7] Harahap, M., Hararak, B., Khan, I., Pandita, S., and Gea, S., 2019, Wet-spinning of cellulose acetate reinforced with acetylated nano-crystalline cellulose as carbon fibre precursors, IOP Conf. Ser.: Mater. Sci. Eng., 553, 012038.

[8] Cao, Q., Zhang, Y., Chen, J., Zhu, M., Yang, C., Guo, H., Song, Y., Li, Y., and Zhou, J., 2020, Electrospun biomass based carbon nanofibers as high-performance supercapacitors, Ind. Crops Prod., 148, 112181.

[9] Salas, C., Ago, M., Lucia, L.A., and Rojas, O.J., 2014, Synthesis of soy protein-lignin nanofibers by solution electrospinning, React. Funct. Polym., 85, 221-227.

[10] Chio, C., Sain, M., and Qin, W., 2019, Lignin utilization: A review of lignin depolymerization from various aspects, Renewable Sustainable Energy Rev., 107, 232-249.

[11] Ko, F.K., Goudarzi, A., Lin, L.T., Li, Y., and Kadla, J.F., 2016, "Lignin-Based Composite Carbon Nanofibers" in Lignin in Polymer Composites, William Andrew Publishing, Oxford, UK, 167-194.

[12] Ilmiati, S., Hafiza, J., Fatriansyah, J.F., Kustiyah, E., and Chalid, M., 2018, Synthesis and characterization of lignin-based polyurethane as a potential compatibilizer, Indones. J. Chem., 18 (3), 390-396.

[13] Trogen, M., Le, N.G., Sawada, S., Guizani, C., Lourençon, T.V., Pitkänen, L., Sixta, H., Shah, R., O’Neill, H., Balakshin, M., Byrne, N., and Hummel, M., 2020, Cellulose-lignin composite fibres as precursors for carbon fibres. Part 1- Manufacturing and properties of precursor fibres, Carbohydr. Polym., 252, 117133.

[14] Poursorkhabi, V., Mohanty, A.K., and Misra, M., 2015, Electrospinning of aqueous lignin/poly(ethylene oxide) complexes, J. Appl. Polym. Sci., 132 (2), 41260.
[15] Misran, E., Wirdjosentono, B., Noor, N.M., Gea, S., Situmorang, S.A., and Harahap, M., 2020, Preparation and characterisation of electrospun composite nanofibre polyvinyl alcohol/nanofibrillated cellulose isolated from oil palm empty fruit bunches, BioResources, 15 (4), 7906-7917.

[16] Fatema, U.K., Uddin, A.J., Uemura, K., and Gotoh, Y., 2011, Fabrication of carbon fibers from electrospun poly(vinyl alcohol) nanofibers, Text. Res. J., 81 (7), 659-672.

[17] Fatimah, I., Sari, T.I., and Anggoro, D., 2020, Effect of concentration and nozzle-collector distance on the morphology of nanofibers, Key Eng. Mater., 860, 315-319.

[18] Ago, M., Okajima, K., Jakes, J.E., Park, S., and Rojas, O.J., 2012, Lignin-based electrospun nanofibers reinforced with cellulose nanocrystals, Biomacromolecules, 13 (3), 918-926.

[19] Lai C., Zhou, Z., Zhang, L., Wang, X., Zhou, Q., Zhao, Y., Wang, Y., Wu, X.F., Zhu, Z., and Fong, H., 2014, Free-standing and mechanically flexible mats consisting of electrospun carbon nanofibers made from a natural product of alkali lignin as binderfree electrodes for high-performance supercapacitors, J. Power Sources, 247, 134-141.

[20] Korbag, I., and Mohamed Saleh, S., 2016, Studies on the formation of intermolecular interactions and structural characterization of polyvinyl alcohol/lignin film, Int. J. Environ. Stud., 73 (2), 226-235.

[21] Roman, J., Neri, W., Derré, A., and Poulin, P., 2019, Electrospun lignin-based twisted carbon nanofibers for potential microelectrodes applications, Carbon, $145,556-564$.

[22] Rampe, M.J., Setiaji, B., Trisunaryanti, W., and Triyono, T., 2011, Fabrication and characterization of carbon composite from coconut shell carbon, Indones. J. Chem., 11 (2), 124-130.

[23] Ko, H.U., Zhai, L., Park, J.H., Lee, J.Y., Kim, D., and Kim, J., 2018, Poly(vinyl alcohol)-lignin blended resin for cellulose-based composites, J. Appl. Polym. Sci., 135 (34), 46655. 
[24] Ago, M., Borghei, M., Haataja, J.S., and Rojas, O.J., 2016, Mesoporous carbon soft-templated from lignin nanofiber networks: Microphase separation boosts supercapacitance in conductive electrodes, RSC Adv., 6 (89), 85802-85810.
[25] Widiyastuti, W., Rois, M.F., Setyawan, H., Machmudah, S., and Anggoro, D., 2020, Carbonization of lignin extracted from liquid waste of coconut coir delignification, Indones. J. Chem., 20 (4), 842-849. 